\title{
Exploration on the Intangible Cultural Heritage Technique of She Ethnic Group in the Teaching of Fashion Design Under the Background of Cross-boundary Integration
}

\author{
JiaYu Chen ${ }^{1,2, *}$ \\ ${ }^{1}$ Fuzhou University of International Studies and Trade, College of Art and Design, Fuzhou, Fujian,350001, China \\ ${ }^{2}$ Fujian Clothing Industry Technology Development Base, Fuzhou, Fujian,350001, China \\ ${ }^{*}$ Corresponding author. Email: chenjiauyu@fzfu.edu.cn
}

\begin{abstract}
In order to study how to integrate the embroidery craftsmanship in the wedding dress of the She ethnic group in Fujian with the fashion design courses, this article further analyzes the value of the embroidery craftsmanship of She ethnic group's wedding clothes by cutting its traditional embroidery patterns. Through field research, the author visited villages characterized with She ethnic group in eastern Fujian Province and sorted out the difficulties in the inheritance of embroidery in their wedding clothes. Based on the research results, a design case of specific fashion courses reforms is analyzed, and the feasibility of applying the intangible cultural heritage She ethnicity wedding clothing embroidery into the fashion design teaching is explored. The methods proposed in this article include the combination of embroidery technology and fashion design, improvement of fashion design modules, and innovative use of pattern technology. Finally, this article suggests that in the education and teaching of clothing design, traditional handicrafts should be integrated with fashion, and the accumulation of traditional cultural ideas and the expansion and promotion of skills should be emphasized in the curriculum, so that skills can be valued and inherited and innovated.
\end{abstract} Keywords: She Embroidery; Fashion design; The education teaching; Inheritance and innovation

\section{INTRODUCTION}

The world is developing rapidly. The fashion trend is developing with each passing day, and the globalization trend presents a scene of convergence and integration. In this era, my country's national culture has developed particularly prominently in the field of fashion. The combination of ethnic embroidery and fashion trend design can show itself in the intricate fashion field. The role of embroidery technology here is to highlight the national characteristics in the environment of multi-element integration. China's national characteristics are based on the world. Embroidery is one of the outstanding national traditional crafts in my country. The four famous embroidery in China are Su embroidery, Yue embroidery, Hunan embroidery, and Shu embroidery[1].Although the current national craftsmanship and cultural inheritance have encountered many problems, the integration of ethnic embroidery and fashion trends in my country is becoming more and more intensive. This is the requirement on the traditional handicrafts and is also the demand for the integration An important measure for the protection of legacy handicrafts is to integrate the embroidery technology of Fujian She ethnicity's wedding dress into contemporary clothing design teaching, thus promoting the inheritance and development of She ethnicity's intangible heritage craftsmanship. Finding an effective application method for this problem is a question worth pondering.

\section{AN OVERVIEW OF THE EMBROIDERY STYLES OF THE WEDDING DRESS OF THE SHE ETHNIC GROUP IN FUJIAN}

\subsection{Abundant subject matter of She embroidery designs}

The author visited villages characterized with She ethnic group in eastern Fujian. Taking Bajing She nationality township in Luoyuan, Fuzhou City, Fujian Province as an example, the She nationality village in Luoyuan area in eastern Fujian has the richest decorative patterns. She women are ingenious and handy. The theme of embroidery patterns mostly comes from the details of daily life. Birds, fish and insects, flowers and plants are mostly inspirational themes of creation. Among them, the more characteristic embroidery styles are reflected in the mythical stories that are widely circulated among the She people. For example, mythological stories such as Liu Hai's play with Golden toad and the Eight Immortals Crossing the Sea all reflect 
the ancestor worship of Panhu by the She people[2]. The legend that the ancestor of the She nationality Panhu king married the third princess of Emperor GaoXin is widely spread among the people of the She nationality. The Third princess wears a phoenix crown and the image of the phoenix dress is also deeply imprinted in the marriage customs of the She nationality. The influence of this myth is far-reaching. The phoenix pattern is the most common in the wedding dresses of the She ethnic group. The styles of phoenix birds are not the same, but they all express the meaning of happiness and joy. The rich auspicious patterns on the traditional wedding dress of the She nationality expresses the good expectations of women for their married life and their best wishes for raising children.

\subsection{Colorful She Embroidery}

The wedding dresses of the She nationality in Fujian are based on navy blue, and the colorful embroidered patterns reflects the ethnic characteristics of the She nationality's "good colorful clothes". In the color design of embroidery styles, the three primary colors of red, red and blue are mainly used. Contrasting colors such as green and orange are used to match the embroidery patterns with strong visual effects. The overall picture style has high saturation, high brightness and rich layers with strong decorative. She women use skilled embroidery techniques to weave colorful embroidery threads into various patterns, such as pillar patterns and human figures.

\subsection{She Embroidery highlights three-dimensional}

The embroidery technique in the traditional wedding dress of She nationality in Fujian is rich and diverse, and the skill of acupuncture is complicated and exquisite. As China attaches importance to intangible cultural heritage and intangible cultural heritage tradition, the She nationality embroidery technology is becoming more and more exquisite. The common embroidery techniques on the She nationality wedding dress are chain embroidery, flat needle embroidery, pan Jinxiu, seed embroidery and other[3], and gradually develop into a series of relatively complete embroidery needlework system. As far as Luoyuan She nationality wedding dress is concerned, flat needle embroidery on apron is the most common embroidery method. The needle method of flat needle embroidery is a continuous needle method with 2-3 stitches at a time with smooth lines and full picture. The author visited Bailukeng half-moon village in Xinan Town, Xiapu County, and found that chain embroidery was used in Xiapu type She nationality wedding dress. In the design of embroidery patterns, She people like to use white thread, gold thread contour decoration, highlighting the pattern of three-dimensional and hierarchical sense.

\section{THE PRESENT SITUATION OF SHE EMBROIDERY INHERITANCE BASED ON THE EASTERN AREA OF FUJIAN}

In order to study the present situation of the intangible cultural heritage inheritors of She nationality costumes in eastern Fujian, the author visited She nationality township, Chongru township, Xiapu county, Ningde city, Fu'an city, Banzhong She nationality township, Lianjiang county, Fuzhou city. Most She people prefer daily casual clothes, and in marriage occasions, they prefer western wedding dresses and suits, which is far from the traditional dress of She nationality.

\subsection{The Dilemma of She's Dress Inheritors in Eastern Fujian}

As far as the present situation of She nationality costume inheritors in eastern Fujian is concerned, only a small number of intangible cultural heritage inheritors have their own clothing enterprises, which can contact suitable commercial cooperation projects in major gatherings or commercial performances. She people are self-sufficient by making orders for national clothing. Most of the intangible cultural heritage inheritors still have their own work, but do not give up the love of She nationality clothing, inherit the embroidery skills of She nationality wedding dress They make time for clothing production in the occasional commercial clothing orders. With the acceleration of the pace of life for contemporary young people, the aesthetic gradually westernized, which is not consistent with the traditional national aesthetic. The candidates who can continue such skills gradually reduced, which troubles the inheritance of She marriage clothing embroidery technique.

\subsection{The Dilemma of She Nationality's Dress sense of identity in Eastern Fujian}

With the rapid development of society, there are fewer people wearing traditional dress. The national dress not only carries the cultural connotation of the nation, but also records the historical fragment of the nation. As far as Xiapu style She nationality dress is concerned, the dress image is big skirt right dress, the fabric is black, and the skirt angle is oblique angle. In addition, it has the representative strong clothing bucket and the front and rear clothing piece is equal length. According to a number of embroidered patterns, it is divided into "one red" with a red lace, "two reds" with two patterns, and "three reds" with three patterns[4]. With the development of national commercial tourism, in terms of form and appearance, the phoenix costume has been completely subverted. It is rare to see the true traditional style of She nationality wedding clothes. In such a mixed trend environment, we encounter lots of obstacles in the inheritance and preservation of She 
nationality dress in Fujian, which makes the She nationality dress lose its original characteristics and damages the integrity of She culture.

\section{THE DESIGN IDEA OF COMBINING SHE NATIONALITY'S INTANGIBLE CULTURAL HERITAGE EMBROIDERY TECHNOLOGY WITH CLOTHING DESIGN COURSES}

The embroidery craftsmanship on the wedding dress of the She ethnic group not only has national cultural characteristics, but also can be passed down as a pattern. Combined with the problems encountered by inheritors, the author makes an analysis and explores the wedding clothes of the She ethnic group in eastern Fujian and finds that the source of the style is mostly related to nature and the daily life of She people. There are also common points in the aesthetics of contemporary fashion trends, but they lack the embodiment of individual elements. In the clothing design teaching of contemporary colleges and universities, we need to figure out how to stimulate students' creative thinking, innovate traditional embroidery elements, and create and design modern national styles that are in line with contemporary fashion and fashionable clothing products with a sense of time and fashion. This is the embroidery craft of the She ethnic group[5].

\subsection{Curriculum Ideas of Combining She Minority Intangible Heritage Embroidery Technology and Clothing Design.}

Following the idea of "professional ability-oriented, design practice as the leading and project curriculum as the main body", the project-based teaching based on the design teaching process is constructed, and the "design proposition construction-design task orientation-basic knowledge preparation-typical case analysis" is established - Design task implementation - Achievement evaluation" series design, which combines curriculum assessment with industry employment benchmarks, connects talent training goals with corporate job requirements, integrates teaching and working processes, and curriculum content and She ethnic intangible cultural heritage embroidery craftsmanship. In addition, it integrates with design, effectively improves the quality of talent training and expands the scope of application, and better meets the employment needs of contemporary apparel companies.

\subsection{Design and production of teaching task implementation}

This project integrates the She nationality's intangible cultural heritage embroidery pattern into the clothing design. According to the work items of the local enterprises, the job responsibilities of the clothing designer and the learning rules of college students, the tasks of this design course are divided into 3 sections: She nationality's intangible cultural heritage embroidery, the innovative design of She's intangible cultural heritage embroidery patterns, and the use of She's intangible cultural heritage patterns in clothing design. Among them, the first two sections are arranged for 8 class hours respectively, and the third section is arranged for 8 class hours. According to the specific order requirements of local enterprises, it usually starts from a single element, gradually deepens into complex patterns by the extraction of key elements to change and innovation, in practice. In this process, the students' comprehensive design ability is continuously improved, and the She ethnic cultural embroidery patterns and contemporary clothing design are enhanced. The sense of integration enhances the overall fashion and international sense of the She pattern in the fashion, thus achieving a harmonious design effect.

\subsection{Features of task section design}

During the implementation of the clothing design teaching module, the cultural background of the She ethnic group will be prepared in the early stage, and the traditional She ethnic embroidery pattern will be appreciated, and the She ethnic embroidery pattern will be extracted and transformed, and used in the pattern design of the fashion. Through the above 4 steps, it will be used in the traditional She ethnic pattern. We should carry out innovative applications, practice practical operations in clothing design courses, and cultivate comprehensive job skills such as material extraction capabilities and design creation of fashion designers. In the teaching process, humanities education is infiltrated into students' classrooms. Through the study of She ethnic traditional embroidery cognition, embroidery patterns and craftsmanship, it stimulates a sense of identity and love for traditional Chinese culture.

\subsection{Cultivate students' interested in She embroidery}

She wedding dress has profound connotation value. It can improve students' ability to appreciate the beauty of the nation, which is particularly important[6]. On the one hand, local colleges and universities should emphasize the importance of intangible cultural heritage inheritance. It is advisable for them to set up relevant courses in colleges and universities, train relevant teachers, and organize a 
series of activities, such as intangible cultural heritage study and research. Teachers and students are called upon to pay more attention to local intangible cultural heritage She clothing and more opportunities should be provided for professional teachers. On the other hand, we should actively train and develop the heritage inheritors on the campus, invite the local technical experts and provincial experts on the dress of the She nationality into the campus, carry out a series of lectures on the dress of the She nationality, spread the connotation of the dress culture of the She nationality, and hold a demonstration class on the embroidery of the She nationality, so as to show and popularize the embroidery skills of the She nationality's wedding dress. By doing so, it will stimulate students' interests in the embroidery of its wedding dress.

\section{CONCLUSION}

As a link in the inheritance of the She ethnic group, the She ethnicity wedding clothes have rich and profound cultural connotations. In the field of clothing design teaching, the method of innovative application of the She ethnicity embroidery styles in contemporary clothing is proposed, which is a fashion design education in line with the times. The traditional elements and modern trends need to be transformed and integrated. In the protection and publicity practice of intangible cultural heritage in recent years, the significance of "intangible cultural heritage on campus" is extraordinary. It has a certain influence on enriching campus cultural connotation, popularizing intangible cultural heritage knowledge, and inheriting intangible cultural heritage skills. There are also many difficulties in integrating embroidery of wedding clothes into the teaching practice of clothing design. By learning the embroidery styles, students can establish a sense of mastership of She ethnic clothing non-inherited, strengthen their aesthetic recognition in She ethnic embroidery elements, and enhance their ability in embroidery, thus preserving and inheriting the cultural connotation of the She nationality, which is still a problem that needs to be solved urgently.

\section{ACKNOWLEDGMENT}

Supported by the 2019 University-level Scientific Research Project < Study on the comparison and inheritance design of embroidery technology between she nationality and hakka wedding dress in modern Fujian>, Fuzhou University of International Studies and Trade, China (No FWX19030).

Supported by the 2019 Open Project Program of Fujian Clothing Industry Technology Development Base, <A study on the comparison and inheritance of stitchwork in modern Fujian traditional wedding clothing>, Minjiang University, China (No. MJXY-KF-201906)

\section{REFERENCES}

[1] Wang Zhe. Deduction and Development of Embroidery Art [J], Popular Arts,2010(16):56.

[2] Chen Yongcheng. Selected Archives [M].] of She Nationality in Fujian Fuzhou: Straits Literature and Art Society 2003:94.

[3] Chen Li, Cui Rongrong. A Study on the Embroidery Technology of She Nationality in Fujian[ J]. China Silk, 2018(5):78-83.

[4] Fang Zeming. Explanation of the source and influence of the "Phoenix costume" of the She nationality [J]. Decoration, 2018(3): 116.

[5] Yuan Jiajia. Research on the Phoenix Pattern of She Nationality in Jingning, Zhejiang and Its Innovative Application in Fashion Design [D]. Shanghai: Donghua University, 2018.

[6] Wang Qin, Wang Jiangyi. Discussion on the protection of the intangible cultural heritage of She nationality costumes[J]. Journal of Hefei Normal University, 2015 (5):48-518. 